\title{
NÚMERO DE MICRORGANISMOS E ATIVIDADE DA UREASE NA PRESENÇA DE ALDICARBE E ENDOSULFAN NO SOLO ${ }^{1}$
}

\author{
T.M.C. SANTOS \\ Departamento de Agronomia, CECA/UFAL, BR 101 Norte, CEP: 57072-970-Macei6,Al \\ R.T.R. MONTEIRO \\ Centro de Energia Nuclear na Agricultura - C.P. 96, CEP: 13416-000, Piracicaba - SP.
}

\begin{abstract}
RESUMO: Avaliou-se o efeito de duas concentraçōes de inseticidas nematicida aldicarbe e do inseticida acaricida endosulfan na população microbiana do solo, através das técnicas de diluição em série e plaqueamento, e através da medida da atividade da enzima urease. Houve um decrescimo na população de actinomicetos com 2ppm de aldicarbe, entretanto com $20 \mathrm{ppm}$ também para endosulfan, a população desses microrganismos aumentou. Para bactérias a adição de aldicarbe nas duas concentraçōes resultou em decréscimo da população; no entanto, para 2 ppm verificou-se recuperaçāo no final do bioensaio e, para $20 \mathrm{ppm}$ o efeito foi considerado irreversível. Na presença de endosulfan verificou-se acréscimo da população bacteriana. Aldicarbe não mostrou ter efeito significativo na população de fungos, enquanto que para endosulfan houve um acréscimo da população fúngica. Os dois inseticidas inibiram drasticamente a população de protozoários. Para os dois inseticidas não foi detectado qualquer efeito na atividade da urease durante o período de incubação.
\end{abstract}

Deacritores: Aldicarbe, endosulfan, microrganismos, urease.

\section{INFLUENCE OF ALDICARB AND ENDOSULFAN ON THE NUMBER OF MICROORGANISMS AND UREASE ACTIVITY IN THE SOIL}

SUMMARY: The effect of two concentrations of aldicarb and endosulfan was evaluated through the dilution in series and urease activity methods. Aldicarb was inhibitory to actinomycetes at $2 \mathrm{ppm}$, but caused a slight stimulation at $20 \mathrm{ppm}$. A stimulation on the actinomycete population was also observed at 2 and $20 \mathrm{ppm}$ of endosulfan. Aldicarb was inhibitory to bacteria in both concentrations but, on the other hand, endosulfan caused stimulation of bacteria and fungi populations; aldicarb was found to have no effect on fungi number. The protozoa were drasticaly affected by both insecticides. The results have shown that both insecticides had no effect on urease activity.

Key Words: aldicarb, endosulfan, microorganisms, urease.

\section{INTRODUÇÃO}

A fertilidade do solo depende não apenas da constituição física e teor de nutrientes, mas também da intensidade do processo biológico que nele ocorre. A urease é a enzima que catalisa a hidrólise da uréia para dióxido de carbono e amônio, sendo produzida por um grande número de microrganismos principalmente bactérias. A distribuição da urease $e$ os fatores que a influenciam tem importância relevante em vista do uso da uréia na agricultura como fertilizante e um dos fatores que podem influenciar a atividade desta enzima no solo é o uso crescente de pesticidas.

Entre os pesticidas mais importantes para agricultura estão incluídos os fungicidas, os herbicidas, os inseticidas e os nematicidas. Todos esses produtos exercem influência sobre os microrganismos existentes no solo e sobre suas atividades. REED et al. (1990) encontra ram relação com a ativi-dade urease no solo com a degradação dos insetici-das carbofuran e ethoprohos. Solos que apresenta-vam alta atividade da urease mostraram velocidade maior da degradação de ambos inseticidas.

\footnotetext{
${ }^{1}$ Parte da Tese de Doutorado do primeiro Autor apresentada à UNESP/Rio Claro.
} 
O presente trabalho teve como objetivo avaliar o efeito dos inseticidas aldicarbe $\mathrm{e}$ endosulfan na população microbiana e na atividade da urease no solo.

\section{MATERIAL E MÉTODOS}

O presente trabalho foi conduzido no laboratório da Seção de Ecologia do Centro de Energia Nuclear na Agricultura da Universidade de São Paulo, Piracicaba, SP, durante 0 ano de 1992.

Foram usados os inseticidas: endosulfan, (Thiodan $350 \mathrm{CE})(6,7,8,9,10,10$ - hexacloro, 5 , 5a,6,9,9a - hexahidro - 6,9 - metano -2,4,3- benzodioxatilpin -3- óxido) e aldicarbe (Temik 150), (2metil - 2 (metiltio) - propionaldeido - 0 - (metilcarbamoil) oxima.

Foram usadas as concentrações de 2ppm (quando aplicadas nas taxas recomendadas, esses produtos raramente atingem mais que $2 \mathrm{ppm}$ FLETCHER, 1960) e 20ppm (correspondente a 10 vezes a concentração máxima, conforme recomendado por LAL, 1988). O controle constou de solo não tratado com inseticida.

O solo utilizado, classificado como terra rocha estruturada série Luiz de Queiroz foi coletado nos primeiros $20 \mathrm{~cm}$ da superfície, com auxilio de uma pá, seco ao ar, peneirado a $2 \mathrm{~mm}$ e sua capacidade de campo determinada pelo método TFM.

A análise química foi realizada pelo Departamento de Química da ESALQ/USP, Piracicaba,SP, incluíndo: $\mathrm{pH}(\mathrm{CaCl}) 6,25$; matéria orgânica 8,73; fósforo 20,8 ; saturação por bases de $89 \%$ e capacidade de troca catrônica de 15,8 $\mathrm{meq} / 100 \mathrm{~cm}^{3}$.

Sub-amostras de solo seco ao ar (100g) foram colocadas em frascos com capacidade para $300 \mathrm{ml}$. O tratamento com o endosulfan foi feito distribuíndo-se $10 \mathrm{ml}$ de solução estoque apropriada de Thiodan, a cada frasco, para acertar a umidade a 2/3 da capacidade de campo; para aldicarbe distribuiu-se os grânulos de Temik no solo, em seguida foi adicionada água destilada para acertar a umidade a $2 / 3$ da capacidade de campo.

o controle recebeu água destilada no volume equivalente a $2 / 3$ da capacidade de campo do solo. Foram usadas 5 repetições para cada tratamento. Os frascos foram mantidos em sala climatizada à temperatura de $25^{\circ} \mathrm{C}$. Após 12,30 , 60,90 e 120 dias para endosulfan e 12, 30,60 e 90 dias para aldicarbe foram coletadas amostras dos mesmos frascos para verificar o efeito dos inseticidas no número e na atividade da enzima urease. A cada 18 dias foi feita pesagem dos frascos com o objetivo de manter constante a umidade em $2 / 3$ da capacidade de campo.

Avaliação da População Microbiana do Solo foi feita através do método de diluição em série, de cada uma das diluições apropriadas foi pipetada uma aliquota de $0,1 \mathrm{ml}$ e semeada em placas de petri contendo meio seletivo para o isolamento de cada grupo de microrganismos Actinomicetos: Meio Amido Caseina de KUSTER \& WILlIANS, (1964); Fungos: Meio de MARTIN; Bactéria: Meio Nutriente Agar e, Protozoários: Ágar água. Foram utilizadas as diluíções $10^{-2}, 10^{-3} \quad 10^{-4}$ para fungos $\mathrm{e}$ actinomicetos; $10^{-4}, 10^{-5}$ e $10^{-6}$ para bactérias e $10^{-1}$, $10^{-2}$ e $10^{-3}$ para protozoários. As culturas de fungos e bactérias foram incubadas a $28^{\circ} \mathrm{C}$, enquanto que as de actinomicetos foram incubadas a $25^{\circ} \mathrm{C}$ por 5 7 dias. Para contagem de protozoários foi utilizado o método de iscas e a população determinada pelo número mais provável (NMP) através da tabela de Fisher e Yates (VICENT, 1970).

Avaliação da Atividade da Urease foi feita pelo método colorimétrico de DOUGLAS \& BREMNER (1970) modificado por TABATABAI (1982).

\section{RESULTADOS}

Para a concentração de 2 ppm de aldicarbe verificou-se uma inibiçãa $\mathrm{da}$ população de actinomicetos em relação ao controle até os 60 dias. Já aos 90 dias observou-se a recuperação da população de actinomicetos (Figura 1A). Pela adição de 20ppm de aldicarbe ao solo observou-se um acréscimo na população de actinomicetos aos 12 , 30, e 90 dias, enquanto que aos 60 dias verificou-se um decréscimo em relação ao controle. Em geral, tanto para os solos tratados com o inseticida como para o controle a população de actinomicetos aumentou durante o período de incubação até os 60 dias. $\mathrm{Na}$ presença de endosulfan (Figura 1B) verificou-se um acréscimo significativo na população de actinomicetos $\mathrm{em}$ relação ao controle para as duas concentrações. Até 90 dias de incubação não houve diferenças significativas entre as duas concentrações testadas. Aos 120 dias de incubação a população de actinomicetos na concentração de 20ppm aumentou consideravelmente. 
A

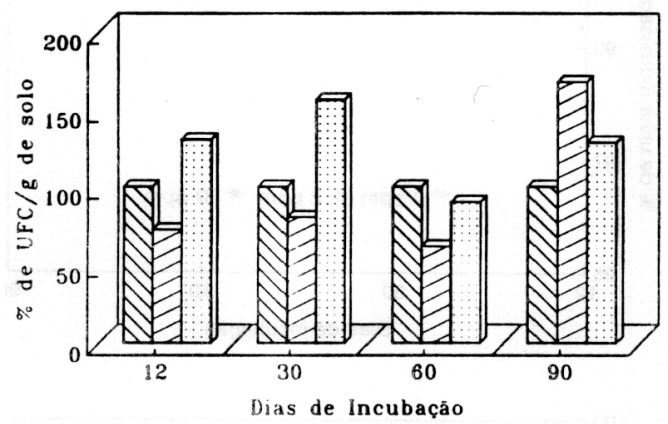

\$0 ppm $\square 2$ ppm $\square 20$ ppm

B

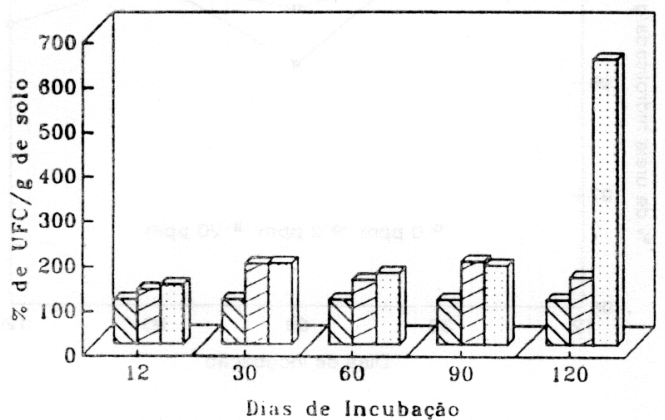

Figura 1 - Percentagem de umidades formadoras de colônia (UFC) de actinomicetos por grama de solo na presença de aldicarbe (A) e endosulfan (B).

$A$ adição 2 ppm de aldicarbe causou um efeito inibitório significativo na população bacteriana (Figura $2 \mathrm{~A}$ ) em relação ao controle até 60 dias. Aos 90 dias verificou-se recuperação da população em número igual ao controle. Na concentração de $20 \mathrm{ppm}$ de aldicarbe causou um significativo efeito inibitório que não diferiu daquelas observados para 2ppm ate os 60 dias, no entanto, para esta concentração não houve recuperação da população bacteriana até aos 90 dias de incubação. A adição de endosulfan (Figura 2B) ao solo não resultou em mudanças significativas na população bacteriana.

Sci. agric., Piracicaba, 51(1):123-130,jan./abr., 1994
A

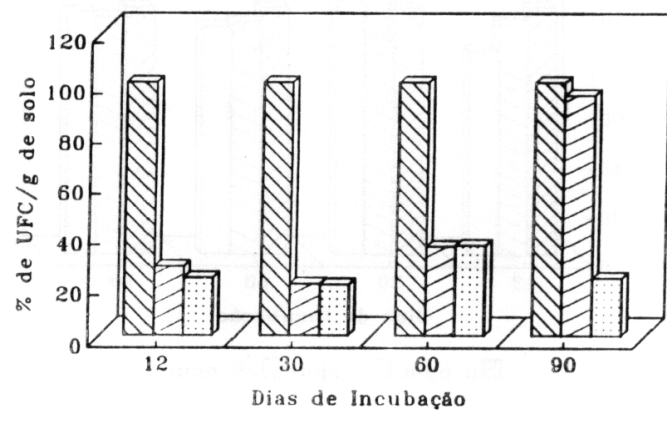

$\square_{0} \mathrm{ppm} \square 2 \mathrm{ppm} \square 20 \mathrm{ppm}$

B

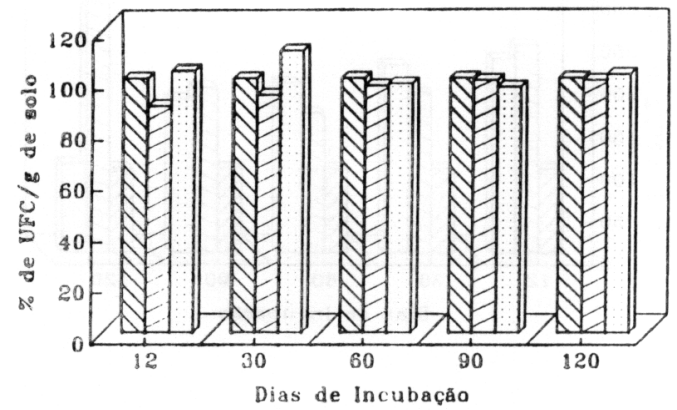

Figura 2 - Percentagem de umidades formadoras de colônia (UFC) de bactérias por grama de solo na presença de aldicarbe (A) e endosulfan (B).

A adição de aldicarbe não apresentou efeitos significativos na população de fungos (Figura 3A). Por outro lado endosulfan causou um acréscimo significativo na população de fungos $\mathrm{cm}$ relação ao controle. (Figura 3B). 0 efeito de aldicarbe e endosulfan na população de protozoários encontra-se na TABELA 1. Observou-se uma forte inibição que variou de 98,61 a $100 \%$ para as duas concentrações durante todo período de incubação.

Os resultados obtidos para a atividade da urease estão apresentados na Figura 4. Tanto a adição de aldicarbe como de endosulfan não tiveram efeito na atividade da urease. 
A

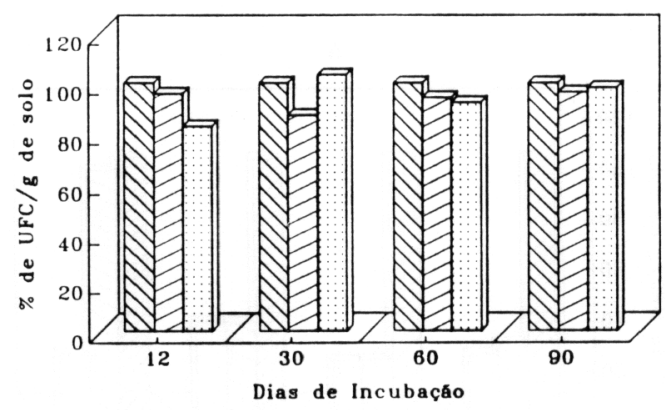

$\triangle 0 \mathrm{ppm} \boxminus 2 \mathrm{ppm} \square 20 \mathrm{ppm}$

B

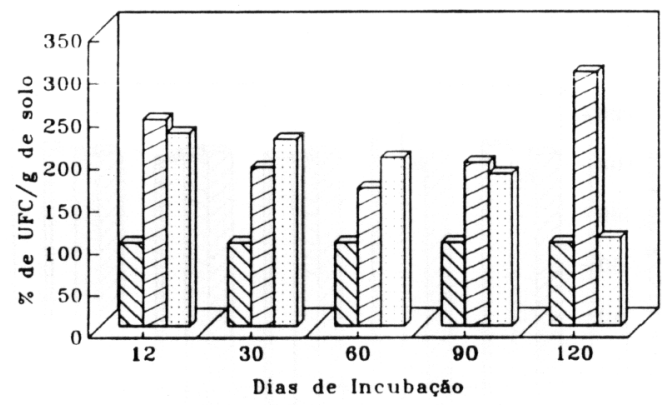

Figura 3 - Percentagem de umidades formadoras de colônia (UFC) de fungos por grama de solo na presença de aldicarbe (A) e endosulfan (B).

A TABELA 2 apresenta os coeficientes de correlação entre $O$ número de actinomicetos, bactérias, fungos e número total de microrganismos. Não foram detectadas correlações significativas entre a atividade da urease $e$ as demais variáveis no bioensaio com aldicarbe. Para endosulfan detectou-se correlações significativas entre a atividade da urease $e, o$ número de actinomicetos (positiva) e o número de fungos para concentração de 20ppm (negativa).

\section{DISCUSSÃO}

Um pesticida pode atuar em duas vias na microflora: de um lado ele pode influenciar os
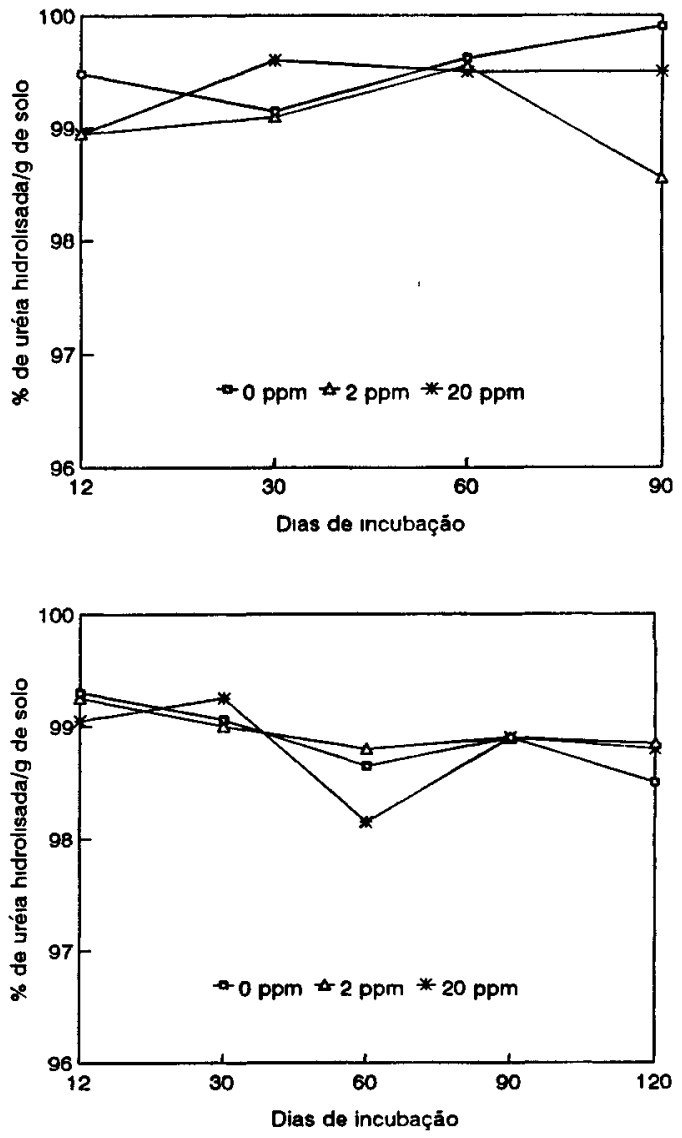

Figura 4 - Efeito de aldicarbe (A) e endosulfan (B) na atividade da urease.

microrganismos responsáveis por sua degradação e essa ação pode também se estender aos organismos envolvidos na degradação de outras substâncias. Por outro lado, o pesticida pode atuar também como um substrato para a microflora do solo. Na verdade sua degradação pode suprir certos organismos com carbono, energia e algumas vezes o nitrogênio necessário para seu crescimento. Em qualquer caso a consequência mais importante desses dois aspectos reside essencialmente na degradação do pesticida (SIMON-SYLVESTRE \& FOURNIER, 1979).

A inibição do crescimento da população microbiana ou de segmentos da mesma vai determinar a persistência do produto no solo, visto que a mineralização ou completa degradação é quase sempre uma atividade microbiana. 
NÚMERO DE MICRORGANISMOS E ATIVIDADE DA UREASE NA PRESENÇA DE ALDICARBE ... 127

TABELA 1 - População média de protozoários $\left(\times 10^{2}\right)$ por grama de solo na presença de aldicarbe e de endosulfan em função do tempo de incubação. Médias de 4 repetições.

\begin{tabular}{ccccccc}
\hline $\begin{array}{c}\text { (TEMPO) } \\
\text { (dias) }\end{array}$ & & Aldicarbe & \multicolumn{3}{c}{ Endosulfan } \\
\hline & 0 & 2 & 20 & 0 & 2 & 20 \\
\hline 12 & 39 & 0,54 & 0,39 & 41 & 0,16 & 0,23 \\
30 & 43 & 0,17 & 0,11 & 54 & 0,58 & 0,18 \\
60 & 61 & 0,61 & 0,46 & 43 & 0,41 & 0,17 \\
90 & 42 & 0,00 & 0,00 & 111 & 0,37 & 0,15 \\
120 & - & - & - & 72 & 0,20 & 0,11 \\
\hline \hline
\end{tabular}

TABELA 2 - Coeficiente de correlação entre o número de unidades formadoras de colônia por grama de solo e atividade da urease nas concentrações de 0,2 e $20 \mathrm{ppm}$.

\begin{tabular}{|c|c|c|c|}
\hline & & \multicolumn{2}{|c|}{ VARIÁVEIS } \\
\hline & & \multicolumn{2}{|c|}{ UREASE } \\
\hline \multirow[t]{2}{*}{ PPM } & & ALDICARBE & ENDOSULFAN \\
\hline & ACTINOMICETOS & 0,457 & 0,339 \\
\hline \multirow[t]{4}{*}{0} & BACTÉRIAS & $-0,176$ & $-0,394$ \\
\hline & FUNGOS & $-0,181$ & 0,329 \\
\hline & $N^{\circ}$ TOTAL DE MICRORGANISMOS & $-0,173$ & 0,395 \\
\hline & ACTINOMICETOS & 0,693 & $-0,289$ \\
\hline \multirow[t]{4}{*}{2} & BACTÉRIAS & 0,635 & $-0,225$ \\
\hline & FUNGOS & 0,695 & $-0,405$ \\
\hline & No TOTAL DE MICRORGANISMOS & 0,634 & $-0,226$ \\
\hline & ACTINOMICETOS & 0,539 & $0,944^{* *}$ \\
\hline \multirow[t]{3}{*}{3} & BACTÉRIAS & 0,618 & 0,525 \\
\hline & FUNGOS & 0,539 & $-0,823 *$ \\
\hline & N' TOTAL DE MICRORGANISMOS & 0,619 & 0,533 \\
\hline
\end{tabular}

*, ** significativo ao nível de 10 e $5 \%$ de probabilidade pelo teste $t$, respectivamente. 
Poucos processos abióticos de importância, convertem totalmente compostos orgânicos de qualquer grau de complexidade a produtos inorgânicos (SIMON-SYLVESTRE \& FOURNIER, 1979).

Os resultados obtidos sugerem que os actinomicetos usaram 20ppm de aldicarbe como fonte de carbono e energia e, $2 \mathrm{ppm}$ foi insuficiente para o desenvolvimento dos microrganismos. Pode ter ocorrido aqui um processo conhecido como enriquecimento que foi primeiro descrito por AUDUS (1949) em seu estudo com desintoxicação de 2,4-D no solo, onde se observa que a adição de certos biocidas ou a presença de certos metabólitos do mesmo no solo, determina a proliferação de certos grupos de microrganismos. Esse fenômeno pode ser usado para explicar os mecanismos de adaptação dos microrganismos do solo, na degradação de muitos produtos e significa que microrganismos utilizam tais substâncias como fonte de energia e carbono. Os resultados obtidos aqui, também concordam com aqueles obtidos por KUSESKE et al., (1974). Estes autores estudando o efeito de aldicarbe, nas concentrações de 5 a $500 \mathrm{ppm}$, verificaram um acréscimo na população de actinomicetos, principalmente após aplicação de $500 \mathrm{ppm}$.

Na presença de endosulfan, verificou-se um acréscimo significativo da população de actinomicetos, para as duas concentrações. Esse resultado também sugere a ocorrência de enriquecimento, porém, para esse inseticida a menor concentração foi suficiente para a proliferação dos actinomicetos; esse fato poderia estar ligado a estrutura química de endosulfan. MONTEIRO et al., (1989) observaram que a degradação de endosulfan ocorre por ação microbiana, sendo o diol o principal metabólico após 120-160 dias de incubação, em três tipos de solo, sendo que as porcentagens mais alta de evolução de ${ }^{14} \mathrm{CO}_{2}$ ocorreu em solo rico em actinomicetos. Esse resultado verificado para os dois inseticidas também poderia ter ocorrido em função da esterilização parcial do solo pelos produtos, eliminando espécies ou grupos competidores favorecendo a proliferação dos actinomicetos.

Em geral, a meia vida de aldicarbe e de seus metabólicos variam de quatro a oito semanas. Após o produto ser incorporado no solo, o aldicarbe é oxidado a sulfóxido de aldicarbe e parte do sulfóxido é então oxidado a sulfona de aldicarbe que têm ação inseticida. $O$ sulfóxido e a sulfona de aldicarbe são hidrolisados através de reações químicas ou ação microbiana formando compostos não tóxicos.

Os resultados obtidos no presente trabalho para a concentração de $2 \mathrm{ppm}$ estão de acordo com essas informações referentes ao período de toxicidade do produto, no entanto, foi observado que para a concentração de $20 \mathrm{ppm}$ a população continuou a sofrer ação inibitória até 90 dias.

Levando em consideração as observações de DOMSCH (1980) que, altos déficits ( $>50 \%$ ) e longo e/ou duradouro período de déficit ( $>60$ dias) ou ambos caracterizam o efeito irreversível de um produto sobre a populaçăo microbiana, pode-se considerar os resultados obtidos para bactérias com $20 \mathrm{ppm}$ de aldicarbe como irreversíveis.

Em geral, os inseticidas organoclorados, entre eles endosulfan, não têm qualquer efeito expressivo ou prolongado no total de bactérias do solo. Espécies ou grupos individuais podem ser atingidos, porém raramente esse efeitos são irreversíveis. O padrão usual é um decréscimo inicial no número total de bactérias seguido de acréscimo até o restabelecimento ao nível inicial (LAL \& SAXENA, 1982).

A população fúngica de um modo geral, é mais sensível a ação de pesticidas do que outros grupos de microrganismos, sendo drasticamente reduzida logo após a aplicação dessas substâncias. E essa sensibilidade parece ser maior quando se trata de inseticidas carbamatos e organofosforados. No entanto, os resultados obtidos indicam que a presença de aldicarbe não afetou a população fúngica. READ (1987) verificou um decréscimo da população fúngica em solos tratados com $10,50 \mathrm{e}$ $100 \mathrm{ppm}$ de aldicarbe, sendo observado que a maior parte do crescimento ocorreu 15 a 30 dias após a aplicação. Com concentrações de 100, 1500 e $2000 \mathrm{ppm}$ o crescimento não foi visível no solo nos primeiros 12 dias. A 5000ppm os fungos não foram visíveis no solo por 5 meses e durante os próximos 6 meses apenas um leve crescimento de espécies de Penicillium foi observado.

Os resultados obtidos neste trabalho, estão de acordo com observações feita por vários autores, que apesar dos inseticidas afetarem mais os fungos do solo do que bactérias e actinomicetos, essa ação não é observada com os inseticidas organoclorados, mesmo quando presentes no solo em altas concentrações. No entanto, isso não implica que todos os grupos de fungos não sejam afetados por esses inseticidas. COWLEY \& LICHTENSTEIN (1970) observaram a inibição da 
população fúngica em concentrações acima de 40ppm dos inseticidas aldrin, lindane, paration, forate e carbaril. Os resultados obtidos no presente trabalho também sugerem que, assim como as actinomicetos, a população fúngica utiliza endosulfan como fonte de carbono e energia. Embora não tenham sido verificadas mudanças quantitativas significativas na população fúngica, tanto na presença de aldicarbe como de endosulfan, ocorreram mudanças qualitati-vas. Foi verificado uma predominância dos gêneros Penicillium e Trichoderma em contraste com uma maior diversidade observada na testemunha. Esse resultado está de acordo com observações feitas por PARR (1981) onde relata que os gêneros Aspergillus, Penicillium e Trichderma predominam em solos tratados com pesticidas.

Verificou-se que a população de protozoários foi altamente sensível aos dois inseticidas nas duas concentrações. Na literatura, são escassos os trabalhos sobre o efeito de pesticidas na população de protozórios, no entanto, sabe-se que esses microrganismos não usam tais produtos como fonte de carbono e energia (LYNCH, 1986).

A ureia pode ser hidrolisada por actinomicetos, bactérias e fungos, sendo as bactérias o grupo mais importante (LOYD \& SHEAFF, 1973). A taxa de bactérias ureolíticas no solo, permanece constante enquanto que a população total pode variar. Desse modo, a atividade da urease, no solo, muitas vezes pode estar associada com o tamanho da população. Por outro lado, foi verificado por REED et al., 1990, que a atividade da urease pode estar relacionada com a degradação dos inseticidas carbofuran e ethoprophos.

Sugerindo que os níveis de atividade de enzimas indígenas específicas do solo podem ser influenciados por certos pesticidas aplicados ao solo ou por seus metabólitos formados através de degradação.

As correlações observadas no presente trabalho, podem indicar que 20ppm de endosulfan favoreceu os actinomicetos produtores de urease, enquanto que os fungos produtores de urease foram inibidos.

\section{REFERÊNCIAS BIBLIOGRÁFICAS}

AUDUS, L.J. The biological detoxication of 2:4-dichloro phenoxyacetic acid in soil. Plant and Soil, The Hague, v.2, p.31-36, 1949.
COWLEY, G.T.; LICHTENSTEIN, E.P. Growth inhibiton of soil fungi by inseticides and annulment of inhibition by yeast extract or nitrogens nutrients. Journal of General Microbiology, London, v.62, p.27-34, 1970.

DOMSCH, K.H. Interpretation and evaluation of data. In: GREAVES, M.P.; POOLE, N.L; DOMSCH, K.H. JAGNOW, G.; VERSTRAETE, W. Recommend tests for assessing the side effects of pesticides on the soil microflora. London, Agricultural Research Council Weed Research Organization, 1980, p.6-15. (Technical Reporter).

DOUGLAS, L.A.; BREMNER, S.M. Extraction and colorimetric determination of urea in soils. Soil Science Society of America Proceedings, Madison, v.34, p.859-862, 1970.

FLETCHER, W.F. The effects of herbicides on soil microorganisms. In: WOODFORD, E.R.; SAGAR, G.R. Herbicides and the soil. Oxford: Blackwell Scientific, 1960. p.20-62.

KUSESKE, D.W.; FUNKE, B.R.; SCHLTZ, I.T. Effects and persistence of baygon (propoxur) and temik (aldicarb) insecticides in soil. Plant and Soil, The Hague, v.41, p.255-269, 1974.

KUSTER, E.; WILLIAMS, S.T. Selection of media for isolation os Streptomycetes. Nature, London, v.202, p.928-929, 1964.

LAL, R. Experimental, methodological, and analytical approach to study the effects of pesticides on nitrogen cucle. In: LAL, R.; LAL, S. Pesticides and nitrogenic cycle. Boca Raton: CRC Press, 1988. p.76-129.

LAL, R.V.P.; SAXENA, D.M. Accumulation, metabolism and effects of organochlorine insectides on microorganisms. Microbiology Review, Washington, v.46, p.95-127, 1982.

LYNCH, J.M. Biotecnologia do solo. São Paulo:Manole, 1986. 209p.

LLOYD, A.B.; SHEAFFE, M.J. Urease activity in soils. Plant and Soil, The Hague, v.39, p.71-80, 1973.

MONTEIRO, R.T.R.; HIRATA, R.; ANDREA, M.M.; WALDER, J.M.M.; WIENDL, F.M. Degradação do inseticida $\left({ }^{4} \mathrm{C}\right)$ endosulfan em três solos do Estado de São Paulo. Revista Brasileira de Ciencia do Solo, Campinas, v.13, p.163-168, 1989.

PARR, J.F. Effects of pesticides on microorganisms in soil and water. In: GUENZI, W.D. Pesticides in soil and water, 2.ed. Madison: Soil Science Society of America, 1981. p.315-340. 
READ, D.C. Greatly accelerated microbial degradation of aldicarb in retreated field soil, in flooded soil and in water. Journal of Economic Entomology, College Park, v.80, p.156-163, 1987.

REED, J.P.; KREMER, R.J.; KEASTER, A.J. Spectrophotometric methodologies for predicting and studying enhanced degradation. In: RACKE, K.D.; COATS, J.R. (Ed.) Enhanced biodegradation of pesticides in the environment. Washington, ACS, 1990. cap.18, p.240-248. (ACS Symposium Series, 426).

SIMON-SYLVESTRE, G.; FOURNIER, J.C. Effects of pesticides on the soil microflora. Advances in Agronomy, New York, v.31, p.1-92, 1979.
TABATABAI, M.A. Soil enzymes. In: PAGE, A.L.; MILLER, R.H.; REENEY, D.R. Methods of soils analysis: chemical and microbiological properties. Madison: American Society of Agronomy, 1982. p.903-947.

VINCENT, J.M. A manual for the practical study of root nodules bacteria. Oxford: Blackwell Scientific, 1970. 164p. (IBP Handbook, n.15).

Enviado para publicação em 16.03 .93

Aceito para publicação em 28.03.94 